\title{
Adsorption Dynamics of Redox Active Species onto Polarized Surfaces of Sensitized NiO
}

\author{
Andrea G. Marrani,*๑ Matteo Bonomo, $\odot$ and Danilo Dini*๑ \\ Dipartimento di Chimica, Università di Roma La Sapienza, p.le A. Moro 5, I-00185 Rome, Italy \\ Supporting Information
}

\begin{abstract}
Mesoporous $\mathrm{NiO}$ films were deposited by means of a screen printing technique onto fluorine-doped tin oxide transparent electrodes and consequently sensitized with Erythrosin B (EryB) dye. The obtained colored $\mathrm{NiO}$ material was used as a working electrode in a three-electrode cell to study the evolution of the triple semiconductor/ dye/electrolyte interface upon electrochemical polarization in dark conditions. The electrolyte was a solution of $\mathrm{I}_{3}^{-} / \mathrm{I}^{-}$in acetonitrile, with the redox couple representing the typical redox shuttle of dye-sensitized solar cells (DSCs). The adopted electrochemical conditions were devised in order to simulate the actual electrical environment of the $\mathrm{NiO} /$ dye photocathode in a light-soaked DSC. The use of a benchmark sensitizer EryB and of the most widely used redox mediator $\mathrm{I}_{3}^{-} / \mathrm{I}^{-}$is particularly meaningful for the study of the adsorption dynamics and the

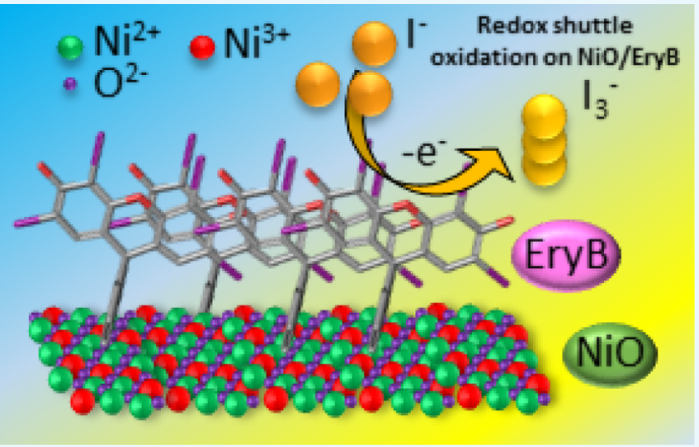
determination of possible degradative phenomena on the basis of the behavior of numerous analogue systems. Therefore, for the first time, the evolution of the $\mathrm{NiO} / \mathrm{EryB} / \mathrm{I}_{3}{ }^{-} / \mathrm{I}^{-}$multiple interface was investigated combining the electrochemical characterization with ex situ spectroscopic analysis by means of X-ray photoelectron spectroscopy. The resulting picture shows that EryB in the immobilized state promotes the redox processes based on the $\mathrm{I}_{3}{ }^{-} / \mathrm{I}^{-}$couple. Moreover, the EryB sensitizer inhibits the phenomena of recombination between the metal oxide semiconductor and the redox couple.
\end{abstract}

\section{INTRODUCTION}

Nickel oxide $(\mathrm{NiO})$ in the configuration of a thin film constitutes a material of great interest for its involvement as the active component in a variety of advanced applications. These include the electrochemical storage of energy, ${ }^{1}$ the modulation of optical transmission via electrical signals in electrochromic windows, ${ }^{2}$ the photoelectrochemical conversion of the luminous radiation into electrical energy ${ }^{3,4}$ or chemicals/fuels, ${ }^{5,6}$ and the conversion of optical signals into electrical signals in optoelectronic devices. ${ }^{7}$ In particular, $\mathrm{NiO}$ thin films with nanostructured morphology ${ }^{8}$ are widely used in photoelectrochemical cells because $\mathrm{NiO}$ represents the benchmark photocathodic material of p-type dye-sensitized solar cells (p-DSCs)..$^{9-13}$ In the context of the DSC application ${ }^{14,15}$ the photoelectrochemical properties of mesoporous $\mathrm{NiO}$ electrodes in the bare state are not sufficiently good to realize an efficient process of photoactivated electroreduction. ${ }^{16}$ Therefore, $\mathrm{NiO}$ necessitates a sensitizer ${ }^{17}$ with opportune structural, optical, and excited-state properties ${ }^{18-20}$ to realize efficaciously the conversion of an optically generated exciton ${ }^{21}$ into two separated charged species of opposite signs and with high mobility. ${ }^{22}$ The successive diffusion of the photogenerated charge carriers toward the respective charge collectors represents the main mechanism with which the photocurrent is transported through a DSC. ${ }^{23}$ In NiO-based pDSCs, the optical excitation of the colorant leads to the simultaneous injection of a hole into the valence band (VB) of mesoporous $\mathrm{NiO}$ and the transfer of an electron to the oxidized (Ox) form of the redox shuttle ${ }^{24}$ (Scheme 1), the redox couple $\mathrm{I}_{3}^{-} / \mathrm{I}^{-}$being the most common choice of the redox mediator for DSCs.

A recent study on the ex situ characterization of DSC electrodes with X-ray diffraction (XRD) techniques showed that sensitized photocathodes of mesoporous $\mathrm{NiO}$ undergo structural reconstruction under the operative conditions of a pDSC and a tandem DSC (t-DSC). ${ }^{26}$ Such a structural modification of $\mathrm{NiO}$ is a consequence of charge photoinjection in the metal oxide when $\mathrm{I}_{3}^{-} / \mathrm{I}^{-}$is the redox shuttle. The observed phenomenon is specific of mesoporous p-type $\mathrm{NiO}^{27}$ whereas n-type photoanodes such as $\mathrm{TiO}_{2}{ }^{26,28}$ or $\mathrm{ZnO}^{29}$ do not present alterations of the XRD spectra following their photoelectrochemical action toward the $\mathrm{I}_{3}^{-} / \mathrm{I}^{-}$couple in DSCs. XPS studies combined with electrochemical analyses also revealed that mesoporous $\mathrm{NiO}$ electrodes in both bare ${ }^{30}$ and sensitized ${ }^{31}$ versions possess defective surface sites that are electroactive in dark conditions ${ }^{11,32}$ and, in the case of the nonsensitized $\mathrm{NiO}$ electrode, represent the preferred sites of ionic adsorption, as well as the actual reaction sites of the dark oxidation of $\mathrm{I}^{-}$into $\mathrm{I}_{3}^{-{ }^{-33,34}}$ It is expected that the modification of the surface properties of $\mathrm{NiO}$ following its sensitization with

Received: September 27, 2018

Accepted: January 10, 2019

Published: January 18, 2019 
Scheme 1. Energy Level Scheme and Mechanism of DyeMediated Electron Transfer (ET) from the VB of a p-Type SC to the Ox Form of a Redox Shuttle with $E_{0, \mathrm{r}}>E_{\mathrm{v}}{ }^{a}$

$$
\mathrm{E}_{\mathrm{C}} \longrightarrow
$$

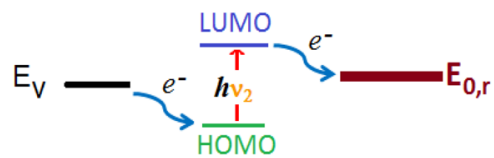

$$
\text { Resulting overall process: } O x+e^{-\stackrel{h v_{2}}{\longrightarrow}} \operatorname{Red}
$$

${ }^{a_{T}}$ The dye sensitizer mediates the ET process via photoinduced excitation of an electron from the HOMO to the LUMO level of the dye $\left(E_{\mathrm{LUMO}}-E_{\mathrm{HOMO}}=h \nu_{2}\right)$. The dye in the transient excited state has a sufficiently high electronic energy to transfer an electron to $\mathrm{Ox}$ at the equilibrium energy $E_{0, \mathrm{r}}$ because $E_{\mathrm{LUMO}}>E_{0, \mathrm{r}}$. The final chemical product of the photoactivated ET process is the reduced form (red) of the redox shuttle.

a colorant will bring about changes in the adsorption properties, $^{35}$ as well as in the mechanisms of charge transfer, charge compensation, and eventual dye desorption ${ }^{31}$ with respect to the bare metal oxide, especially when sensitized $\mathrm{NiO}$ is electrochemically polarized in an electrolyte containing a redox couple. In this framework, a further progress on the understanding of the adsorption/electrochemical phenomena occurring at a modified $\mathrm{NiO}$ electrode can be obtained by the combined spectroscopic analysis of the surface of sensitized $\mathrm{NiO}$ and the determination of its electrochemical properties when the sensitized electrode is electrochemically polarized in the presence of redox species. To our knowledge, at present, no spectroscopic analyses of sensitized mesoporous $\mathrm{NiO}$ have been reported when the reference redox couple $\mathrm{I}_{3}^{-} / \mathrm{I}^{-}$is present in the electrolyte and sensitized $\mathrm{NiO}$ undergoes a treatment of electrochemical oxidation in dark conditions. For the realization of this type of study, we have considered the sensitization of nanostructured $\mathrm{NiO}$ electrodes with the Erythrosin B (EryB) dye $\mathrm{e}^{36,37}$ that represents the commercial benchmark of $\mathrm{NiO}$ sensitizers for p-DSC purposes and the application of a highly surface- and chemical environmentsensitive technique, such as X-ray photoelectron spectroscopy (XPS).

\section{EXPERIMENTAL SECTION}

Preparation of the NiO Film and Sensitization with the Dye. $\mathrm{NiO}$ thin films with mesoscopic features (see Figure S1) were deposited onto fluorine-doped tin oxide (FTO)coated glass specimens via screen-printing according to the procedure reported in refs. ${ }^{38-40}$ The screen-printed electrodes were sensitized via dipping in a $0.2 \mathrm{mM}$ solution of EryB in ethanol for $16 \mathrm{~h}$. The dye molecules which were not chemisorbed on the electrode were removed by rinsing the electrode with pure ethanol after the step of sensitization. All chemicals were purchased from Sigma-Aldrich or Fluka at the highest degree of purity available and were used without any further purification.
Electrochemical Characterization of $\mathrm{NiO}$ Electrodes. The electrochemical properties of EryB-sensitized $\mathrm{NiO}$ thin films were studied with a three-electrode cell configuration: $\mathrm{NiO} /$ EryB-covered FTO was used as a working electrode, a $\mathrm{Pt}$ wire was used as a counter electrode, and $\mathrm{Ag} / \mathrm{AgCl}$ was used as a reference electrode. The electrolyte used was a mixture of 1 $\mathrm{M} \mathrm{LiI}$ and $0.1 \mathrm{M} \mathrm{I}_{2}$ in acetonitrile (ACN).

The applied potential values here reported are all referred to the $\mathrm{Ag} / \mathrm{AgCl}$ electrode $\left(E_{\mathrm{Ag} / \mathrm{AgCl}}\right.$ vs normal hydrogen electrode $=0.21 \mathrm{~V})$. The $\mathrm{NiO}$ films that did not undergo any electrochemical treatment were taken as reference samples in order to analyze with XPS the nature of spontaneous adsorption phenomena. Reference samples were of two types: (a) freshly sensitized $\mathrm{NiO}$ films (here indicated as $\mathrm{NiO} /$ EryB samples) and (b) EryB-sensitized $\mathrm{NiO}$ films dipped in the electrolytic solution $1 \mathrm{M} / 0.1 \mathrm{M} \mathrm{LiI} / \mathrm{I}_{2}$ in $\mathrm{ACN}$ and successively rinsed in pure $\mathrm{ACN}$ (here denominated $\mathrm{NiO} /$ $\mathrm{EryB} /$ sol samples). The reference $\mathrm{NiO} / \mathrm{EryB} /$ sol samples for XPS analysis reproduce the cathode of the p-DSC in dark conditions and at open circuit, that is, with no photovoltage and null photocurrent. The freshly prepared $\mathrm{NiO} /$ EryB samples underwent the following electrochemical treatments: (i) 1 scan and successive 50 continuous scans of cyclic voltammetry at the rate of $0.02 \mathrm{~V} \mathrm{~s}^{-1}$ within the potential range $-0.27 \leq E \leq 1.13 \mathrm{~V}$ versus $\mathrm{Ag} / \mathrm{AgCl}$, with the initial and the end potentials corresponding to the open-circuit potential (OCV) of the cell. The reference samples labeled with CV 1 and CV 50 indicate the electrode after 1 voltammetric scan and 50 voltammetric cycles, respectively. (ii) Chronoamperometry at $E_{\text {appl }}=0.9 \mathrm{~V}$ versus $\mathrm{Ag} / \mathrm{AgCl}$ with the recording of current for a duration of $8000 \mathrm{~s}$ (the sample undergoing the oxidative potential step is labeled as $\mathrm{Ox}$ ). The choice of this value of potential is motivated by the fact that it corresponds to the electrical potential at which the second oxidation wave of pristine $\mathrm{NiO}$ occurs (vide infra). ${ }^{41-46}$ (iii) One voltammetric scan $\left(1\right.$ cycle) at the rate of $0.02 \mathrm{~V} \mathrm{~s}^{-1}$ with the applied potential going from OCV to $1.13 \mathrm{~V}$ and back-reversed to $-0.27 \mathrm{~V}$ versus $\mathrm{Ag} / \mathrm{AgCl}$. After the scan, the potential of the electrode was kept at a final value of $-0.27 \mathrm{~V}$ for $8000 \mathrm{~s}$. The thereby obtained sample is denominated here as Red. After the electrochemical treatments, all samples were rinsed with pure $\mathrm{ACN}$ and dried with a stream of nitrogen. In the following text, all potential values will be referred to the $\mathrm{Ag} / \mathrm{AgCl}$ reference electrode. Cyclic voltammetry and chronoamperometric curves were recorded with the potentiostat/galvanostat Autolab PGSTAT $128 \mathrm{~N}$ and analyzed with the software NOVA 1.9.

All the samples were mounted onto the XPS sample holder with an adhesive scotch tape and a drop of silver paste to ensure electrical contact. The sample was uploaded in the XPS lock chamber as quick as possible to avoid eventual surface contamination from the ambient atmosphere.

X-ray Photoelectron Spectroscopy. XPS measurements were performed with a modified Omicron NanoTechnology MXPS system equipped with a dual X-ray anode (Omicron DAR 400) and an Omicron EA-127 7-channeltron energy analyzer. XP spectra were acquired using $\mathrm{Mg} \mathrm{K} \alpha$ photons ( $h \nu$ $=1253.6 \mathrm{eV})$ as the excitation source, generated with the anode operating at $14 \mathrm{kV}$ and $14 \mathrm{~mA}$. No charging was experienced during measurements. For all the samples, the spectral regions associated with the ionization of $\mathrm{Ni} 2 \mathrm{p}, \mathrm{I} 3 \mathrm{~d}, \mathrm{I}$ $4 \mathrm{~d}, \mathrm{O} 1 \mathrm{~s}$, and $\mathrm{C} 1 \mathrm{~s}$ levels were acquired using an analyzer pass energy of $20 \mathrm{eV}$. A survey scan at $50 \mathrm{eV}$ of pass energy was also taken. A take-off angle $(\theta)$ of $21^{\circ}$ with respect to the direction 
normal to the surface was considered. The measurements were performed at room temperature, and the base pressure in the analyzer chamber was about $2 \times 10^{-9}$ mbar during the recording of the spectra. The binding energy $(\mathrm{BE})$ of the $\mathrm{Ni}$ $2 \mathrm{p}_{3 / 2}$ peak at $854.0 \mathrm{eV}$, associated with the $\mathrm{cd}^{9} \underline{\mathrm{L}}$ final state configuration in $\mathrm{NiO}^{30}$ was used as an internal standard reference for scaling the $\mathrm{BE}$ (accuracy of $\pm 0.05 \mathrm{eV}$ ). The experimental spectra were theoretically reconstructed by fitting the secondary electron background to a linear or a Shirley function (subtracted from the experimental spectrum after optimization) and to elastic peaks with symmetric pseudoVoigt functions described by a common set of parameters [position, full width at half-maximum (FWHM), and Gaussian-Lorentzian ratio] free to vary within narrow limits. The Gaussian-Lorentzian ratio varied between 0.7 and 0.8 . XPS atomic ratios between relevant element components was estimated from experimentally determined area ratios (with $\pm 10 \%$ as associated error), which were corrected for the corresponding photoelectron cross sections according to Scofield calculations ${ }^{47}$ and for the square root dependence of the photoelectron kinetic energy.

Electron Microscopy. Morphological investigation of $\mathrm{NiO}$ thin films was performed using a field-emission scanning electron microscope Zeiss Auriga 405 (c/o SNN-Lab-Sapienza Nanoscience \& Nanotechnology Lab).

\section{RESULTS AND DISCUSSION}

Electrochemical Characterization of NiO/EryB Electrodes. The electrical potential of EryB-sensitized $\mathrm{NiO}$ and bare $\mathrm{NiO}$ was cycled in the range $-0.27 \leq E \leq 1.13 \mathrm{~V}$, and the corresponding variations of current were recorded and are shown in the voltammograms of Figure 1 when the electrolyte

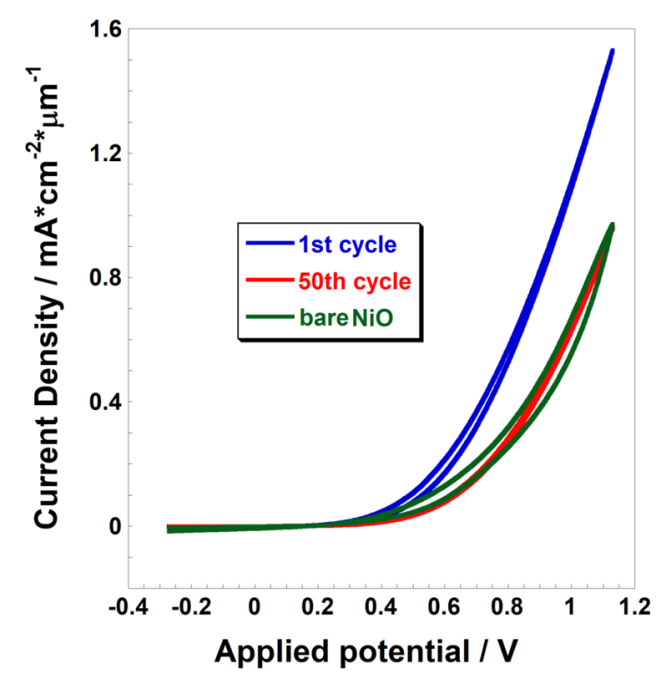

Figure 1. Voltammograms of EryB-sensitized $\mathrm{NiO}$ and bare $\mathrm{NiO}$ in the electrolyte $1 \mathrm{M} \mathrm{LiI/0.1} \mathrm{M} \mathrm{I}_{2}$ in $\mathrm{ACN}$. The scan rate was $20 \mathrm{mV}$ $\mathrm{s}^{-1}$.

was $1 \mathrm{M} \mathrm{LiI/0.1} \mathrm{M} \mathrm{I}_{2}$ in ACN. The voltammograms presented in Figure 1 refer to the 1st and the 50th cycle of EryBsensitized $\mathrm{NiO}$ (blue and red profiles) and to the 1st voltammetric cycle of bare $\mathrm{NiO}$ (dark green curve). The onset of current is the same for all three voltammograms (ca. $0.25 \mathrm{~V}$ ) and refers to the two-electron oxidation of iodide according to ${ }^{33}$

$$
3 \mathrm{I}^{-} \rightarrow \mathrm{I}_{3}^{-}+2 \mathrm{e}^{-}
$$

The shape of the three voltammograms is typical of an irreversible electrochemical process that is originated by the redox active species adsorbed and immobilized on the electrode surface. ${ }^{48,49}$ The electrochemical oxidation of iodide follows the first oxidation of the $\mathrm{NiO}$ electrode (either in the bare or in the sensitized state), which involves a much lower amount of current with respect to iodide oxidation. ${ }^{33,34}$ For this reason, such a NiO-based electrochemical process is barely detectable in the full current scale of the voltammograms that refer to the oxidation of iodine at $\mathrm{NiO}$ electrodes. ${ }^{33}$ In addition to that, oxidation of iodide overlaps with the second process of $\mathrm{NiO}$ oxidation because both processes occur in the same range of electrical potential. ${ }^{33,34}$ The electrical current originated by the second oxidation of $\mathrm{NiO}$ (either in the bare or in the sensitized state) is considerably smaller than the current of iodide oxidation and thus cannot be evidenced in the voltammogram of Figure $1 .^{33,34}$ When the 1st voltammetric cycles of bare and EryB-sensitized $\mathrm{NiO}$ are compared (Figure 1 , dark green and blue traces, respectively), the current generated at the EryB-sensitized electrode is larger than the one generated at bare $\mathrm{NiO}$. This result could be a consequence of several concomitant causes: (i) the rate of electron transfer (et) between iodide and $\mathrm{NiO}$ is larger when EryB sensitizes $\mathrm{NiO}$, with respect to the bare oxide (this would imply an electrocatalytic effect of EryB); (ii) the amount of adsorbed iodide, that is, the redox active species, is higher when $\mathrm{NiO}$ is sensitized by EryB compared to the bare oxide (the effect of surface concentration, which is exerted by immobilized EryB); (iii) the iodine atoms present in the EryB molecule (Figure 2) are somehow involved as initiators/mediators of iodide oxidation onto $\mathrm{NiO}$ (the catalytic effect of EryB).<smiles>COc1c(I)cc2c(-c3ccccc3C(=O)O[Na])c3cc(I)c(=O)c(I)c-3oc2c1I</smiles>

Figure 2. Molecular structure of the EryB sensitizer.

It is well established that the EryB sensitizer acts as a passivating agent of mesoporous $\mathrm{NiO}$, as far as the electrochemical oxidation of $\mathrm{NiO}$ is concerned, when no redox species are present in the electrolyte. ${ }^{11}$ In these conditions, the occurrence of the electrochemical oxidation of $\mathrm{NiO}$ implies the uptake of charge compensating anions that get either adsorbed on the oxide surface or intercalated within the structure of oxidized $\mathrm{NiO}$. The presence of a (mono)layer of immobilized EryB, then, disfavors the process of charge compensation in oxidized $\mathrm{NiO}$ because its presence would prevent intercalation phenomena in $\mathrm{NiO}$ with the EryB layer acting as a blocking agent. The uniform presence of surface localized EryB molecules was deduced from the attenuation of the typical voltammetric oxidation peaks of $\mathrm{NiO}$ upon loading of EryB onto the electrode surface. ${ }^{50}$ Such uniformly distributed EryB layer does not allow the formation of the ionic couples 
generated upon direct contact of positively charged sites of oxidized $\mathrm{NiO}$ with the anions from the electrolyte. It is known that immobilized EryB does not possess any electrochemical activity in correspondence of the potential range within which the NiO substrate oxidizes. ${ }^{11}$ These electrochemical characteristics of the EryB-sensitized $\mathrm{NiO}$ lead us to exclude the existence of an important electrocatalytic effect of immobilized EryB when iodide is oxidized at sensitized $\mathrm{NiO}$ [cause (i), vide supra]. In fact, the possible electrocatalytic effect of immobilized EryB would have manifested itself through the occurrence of charge-transfer processes between the EryB sensitizer and oxidized $\mathrm{NiO}$, with the detection of either an increase of $\mathrm{NiO}$ oxidation current on passing from bare to the EryB-sensitized state or EryB-based redox processes also in absence of a redox species (like iodide) in the electrolyte. Under these circumstances, hypotheses (ii) and (iii) represent the most probable causes at the basis of the increase of anodic current for the electrochemical oxidation of iodide on passing from bare to EryB-sensitized $\mathrm{NiO}$. In particular, it is expected that the adsorption of iodide and the desorption of triiodide (the product of $\mathrm{I}^{-}$oxidation) are the main factors that control the electrochemical behavior of EryB-sensitized $\mathrm{NiO}$ in presence of redox species. The continuous electrochemical cycling of EryB-sensitized $\mathrm{NiO}$ in the iodine/iodide electrolyte brings about a drop of iodide oxidation current (Figure 1, comparison of blue and red profiles). This evolution of the $\mathrm{NiO} /$ EryB voltammograms can be due to several reasons, such as the partial detachment of the EryB layer ${ }^{31}$ or the progressive passivation of the $\mathrm{NiO} /$ EryB surface against further iodide oxidation because of the irreversible immobilization of triiodide, that is, the product of iodide oxidation, on the surface of $\mathrm{NiO} /$ EryB. From the analysis of the XPS data (vide infra), it results that continuous cycling of the $\mathrm{NiO} / \mathrm{EryB}$ electrode in the range of iodide oxidation leads to the increase of triiodide concentration, likely due to triiodide molecules that remained trapped at the surface of $\mathrm{NiO} /$ EryB after their formation. The onset of potential for the oxidation of iodide shifts to higher values (from 0.4 to $0.6 \mathrm{~V}$ ) when the electrode undergoes multiple cycles: this is because an increasing number of oxidizing $\mathrm{Ni}$ (III) sites remains localized at the oxide surface even upon reversal of the potential scan. The electrochemically formed $\mathrm{Ni}$ (III) states are not reversibly reduced to $\mathrm{Ni}$ (II) because of the strong adsorption of triiodide on $\mathrm{NiO} /$ EryB and the built-up of stable ionic couples $\mathrm{Ni}(\mathrm{III}) /$ $\mathrm{I}_{3}{ }^{-}$. These features will be further analyzed in more detail in the XPS section (vide infra).

The oxidative polarization of $\mathrm{NiO} / \mathrm{EryB}$ at $0.9 \mathrm{~V}$ was carried out, and the chronoamperometric curve has been recorded during the first $8000 \mathrm{~s}$ of the potentiostatic experiment (Figure 3) to check which iodine-based species are adsorbed on the surface of the EryB-modified $\mathrm{NiO}$ electrode. In the case of bare $\mathrm{NiO}$, it has been previously found that $\mathrm{I}^{-}$adsorbs onto the $\mathrm{NiO}$ surface prior to the occurrence of its oxidation. ${ }^{33}$ Once iodide is transformed into triiodide, the product of oxidation $\mathrm{I}_{3}{ }^{-}$does not easily desorb from the electrode surface of bare $\mathrm{NiO}$.

At the starting point $t=0$, the current density is $8 \mathrm{~mA} \mathrm{~cm}^{-2}$ in accordance with the value recorded in the first voltammetric cycles. Then the current density rises till it reaches a first plateau at ca. $500 \mathrm{~s}$. This is ascribed to the process of $\mathrm{Ni}(\mathrm{III})$ formation that initiates the oxidation of iodide. At $t>500 \mathrm{~s}$, a further increase of current density is recorded for the occurrence of iodide oxidation at the inner layers of the

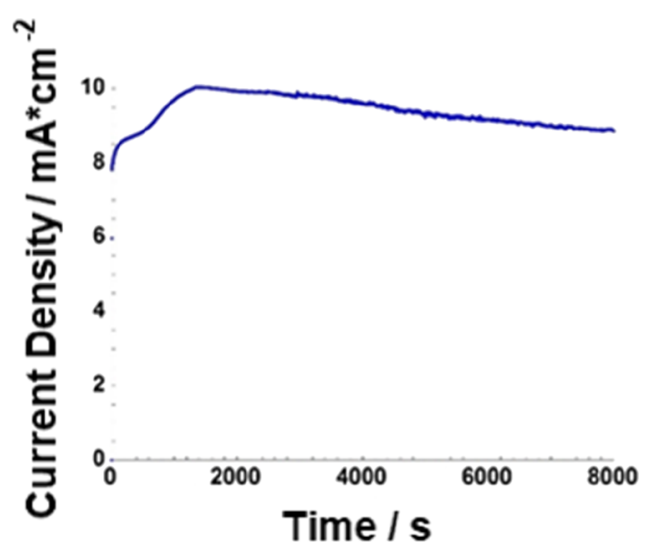

Figure 3. Chronoamperometric curve of the cell with the $\mathrm{NiO} / \mathrm{EryB}$ working electrode when the potential of polarization is $0.9 \mathrm{~V}$. Electrolyte composition: $1 \mathrm{M} \mathrm{LiI/0.1} \mathrm{M} \mathrm{I}_{2}$ in ACN. This potentiostatic experiment served for the preparation of the Ox sample.

porous electrode with the second maximum of current at ca. $1400 \mathrm{~s}$. The steady decline of current at $t>1800 \mathrm{~s}$ is ascribed to the saturation of the surface sites on which iodide oxidation occurs because of the strong adsorption of the product of oxidation $\mathrm{I}_{3}{ }^{-}$on the electrode surface. After oxidation, the $\mathrm{NiO} /$ EryB electrode was then polarized at $-0.2 \mathrm{~V}$, and the chronoamperometric curve was recorded during the first 8000 $s$ of the potentiostatic experiment (Figure 4).

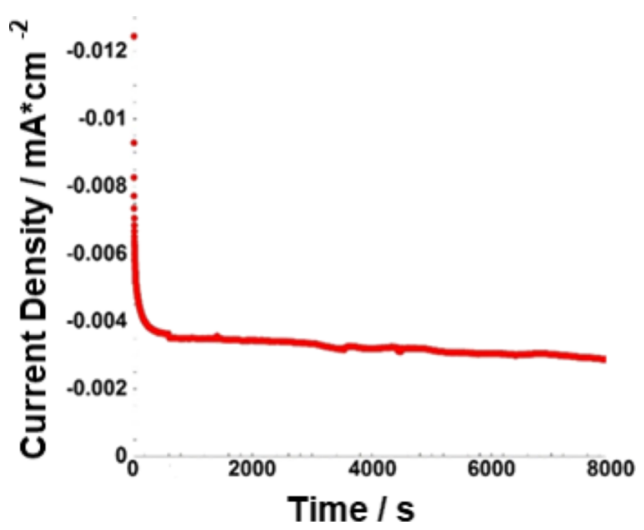

Figure 4. Chronoamperometric curve of the cell with the NiO/EryB working electrode when the potential of polarization is $-0.2 \mathrm{~V}$. Electrolyte composition: $1 \mathrm{M} \mathrm{LiI} / 0.1 \mathrm{M} \mathrm{I}_{2}$ in ACN. This potentiostatic experiment served for the preparation of the Red sample.

The values of current density recorded during the potentiostatic experiment of Red sample preparation are much lower than in the experiment of oxidative polarization. In these conditions, the desorption of unreacted iodide and triiodide is the sole process that can occur at the negatively polarized electrode of $\mathrm{EryB} / \mathrm{NiO}$, in accordance with the voltammograms of Figure 1. At this cathodic polarization, the iodide anions that adsorbed spontaneously onto the native and electrochemically generated defects of $\mathrm{NiO} / \mathrm{EryB}$ get desorbed completely from the sensitized surface of $\mathrm{NiO}$ (vide infra XPS analysis). Different from bare $\mathrm{NiO}$, the presence of the EryB dye prevents the irreversible adsorption of iodine-based species when the $\mathrm{NiO} /$ EryB electrode is polarized cathodically after the oxidation step. The modest variations of the current upon cathodic polarization of previously oxidized $\mathrm{NiO} / \mathrm{EryB}$ reveal 
that no reduction of $\mathrm{Ni}$ (III) takes place (in absence of the reverse redox process). In conclusion, the cathodic polarization of oxidized $\mathrm{NiO} / \mathrm{EryB}$ at $-0.2 \mathrm{~V}$ produces only an electrostatic effect of anion desorption that is completed after $500 \mathrm{~s}$ of polarization (Figure 4), but it does not provoke the redox/ faradic process of $\mathrm{Ni}$ (III) reduction (vide infra).

XPS Analysis of NiO/EryB Electrodes. XPS was used in order to investigate the possible interaction between the different iodinated molecular species adsorbed onto the $\mathrm{NiO}$ porous thin films, such as the EryB dye and the redox mediator couple $\mathrm{I}_{3}^{-} / \mathrm{I}^{-}$, and to ascertain the effect exerted on their relative concentrations by the application of different electrochemical treatments. Such treatments were devised so as to simulate possible real conditions during operation within a real p-DSC. To these aims, the XPS technique is the most suitable mean because it enables a fine and surface-sensitive investigation of chemical environment and oxidation state. On the other hand, XPS was used as an ex situ technique, resulting in a precious and irreplaceable mean to approach the comprehension of the studied phenomena. The most relevant photoionization regions reported in this work are those related to the iodine atoms of the EryB dye and the redox couple, in particular the I $4 \mathrm{~d}$ and I $3 \mathrm{~d}$ regions, and those associated with the $\mathrm{NiO}$ substrate, that is, the $\mathrm{Ni} 2 \mathrm{p}$ region.

As an informative sketch of the elemental fingerprints present in the sample, Figure 5 reports a survey spectrum of

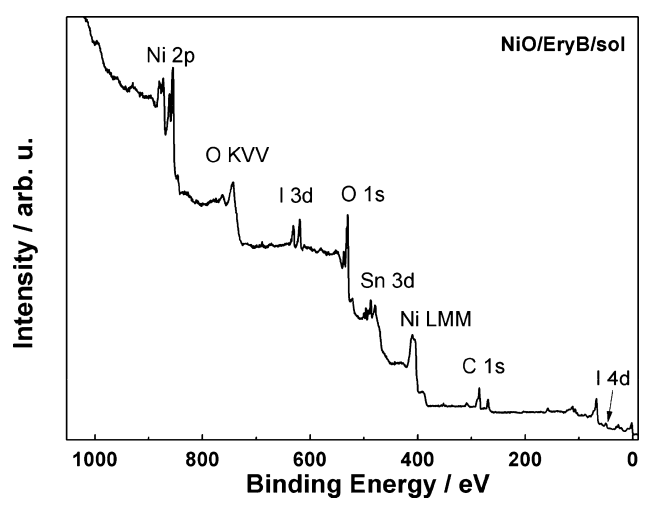

Figure 5. Survey $\mathrm{XP}$ spectrum of the $\mathrm{NiO} / \mathrm{EryB} /$ sol sample. The most relevant signals are identified.

the $\mathrm{NiO} / \mathrm{EryB} / \mathrm{sol}$ sample, taken as representative of the systems addressed in this work. Signals from the substrate, the adsorbed dye, and the redox couple can be identified, together with minor contributions from $\mathrm{Sn}$ because of possible microscopic scratches exposing the underneath surface of the FTO glass substrate to the X-ray beam.

I $4 d$. Hereafter, the XP spectra derived from the ionization of the I $4 \mathrm{~d}$ orbital within the different samples are commented. Even if its photoionization cross section is lower than the I $3 \mathrm{~d}$ orbital one, the I $4 \mathrm{~d}$ spectrum is far more commented in the literature of iodine compounds, probably due to the propensity of the I $4 \mathrm{~d}$ orbital to be characterized under shape-resonance conditions $^{51}$ and its higher sensitivity to changes in the chemical environment, which make it a more reliable probe of the chemical state than the I 3d level. ${ }^{33,52-55}$ Recently, we reported and commented on the I $4 \mathrm{~d}$ spectral features related both to the $\mathrm{I}_{3}{ }^{-} / \mathrm{I}^{-}$redox couple contacted to bare unsensitized $\mathrm{NiO}^{33}$ and to EryB-sensitized $\mathrm{NiO}$ immersed in an inert electrolyte. $^{31}$ Therefore, we aim here at extending and implementing this highly chemically sensitive approach to the understanding of the basic mechanisms of the evolution of the semiconductor/dye/electrolyte interface upon conditions, which match as close as possible those of a real DSC under operation.

Figure 6 shows the I 4d XPS region of the NiO/EryB/sol sample, taken as the prototypical example of the unreacted

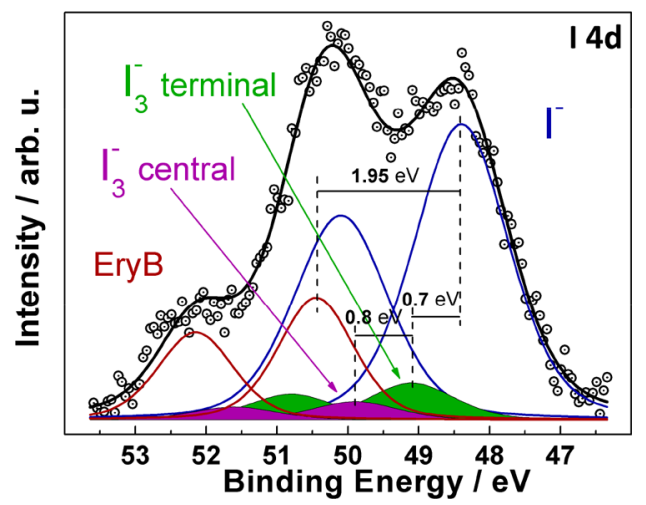

Figure 6. I $4 \mathrm{~d} \mathrm{XP}$ region for the sample $\mathrm{NiO} / \mathrm{EryB} /$ sol. The experimental data (dots) have been theoretically reconstructed with a series of spin-orbit doublets $(j=5 / 2$ and $3 / 2)$ via a peak-fitting procedure (continuous lines). Blue: $\mathrm{I}^{-}$; green: terminal $\mathrm{I}^{2}$ atoms in $\mathrm{I}_{3}^{-}$; magenta: central $\mathrm{I}$ atom in $\mathrm{I}_{3}^{-}$; red: $\mathrm{I}$ atoms in EryB.

pristine system, simply obtained from dipping the sensitized $\mathrm{NiO}$ film into the electrolyte solution. For the sake of a clearer comprehension of the forthcoming spectra, the various components used to reconstruct the experimental data are here described. All the iodinated species present in the system are found to contribute to the intensity recorded with spinorbit split doublets $(j=5 / 2,3 / 2$ for d-type orbitals, with the branching ratio close to 1.5 ) whose components are separated by $1.7 \mathrm{eV} .^{54,56-59}$ We will hereafter refer to the sole $j=5 / 2$ component.

The first more intense contribution at $48.40 \mathrm{eV}$ (see Table 1) comes from the iodide $\left(\mathrm{I}^{-}\right)$ions, which adsorb on the surface of $\mathrm{NiO}$ because of their relatively high concentration in the solution and their relatively concentrated negative charge, which enables an electrostatic interaction with native partially compensated $\mathrm{Ni}(\mathrm{III})$ defects within the porous $\mathrm{NiO} .{ }^{33}$ Upon increasing the $\mathrm{BE}$, the other chemically shifted components found are $\mathrm{I}_{3}{ }^{-}$ions $(\Delta \mathrm{BE}=+0.7 \mathrm{eV})$ and the EryB molecule $(\Delta \mathrm{BE}=+1.95 \mathrm{eV})$. In particular, the $\mathrm{I}_{3}^{-}$molecule has inequivalent I atoms, which contribute the overall intensity envelope at different BEs. In fact, the central I atom is less negative than the two equivalent terminal atoms, and its $\mathrm{BE}$ is positively shifted by $0.8 \mathrm{eV}$ from the terminal ones. ${ }^{33}$ Therefore, the most easily ionizable iodinated species is the $\mathrm{I}^{-}$anion, which bears the highest negative charge density, hence displaying the lowest BE. On the other side, I atoms in the EryB molecule are covalently bound to $\mathrm{C}$ atoms, therefore experiencing a minor fraction of negative charge, which increases their $\mathrm{BE}$ compared to $\mathrm{I}^{-}$and $\mathrm{I}_{3}{ }^{-}$. The $\mathrm{BE}$ position of the three iodinated species is fully consistent with the literature. ${ }^{31,33}$ Quantitatively, the relative molar amount of the species adsorbed onto the electrode is fully favorable to the $\mathrm{I}^{-}$ ion (see Table 2), which is found in a ratio to its counterpart $\mathrm{I}_{3}{ }^{-}$higher than expected from the relative concentrations in solution, consistently with what was previously found for unsensitized $\mathrm{NiO}^{33}$ As to the EryB component, this is as well 
Table 1. BE Values (eV)/FWHM Values $(\mathrm{eV})$ of the I $4 \mathrm{~d}_{5 / 2}$ XPS Components Used To Deconvolute the I $4 \mathrm{~d}$ XP Spectra of the Samples Studied in This Work

\begin{tabular}{|c|c|c|c|c|c|c|}
\hline \multicolumn{7}{|c|}{ samples } \\
\hline assignment & $\mathrm{NiO} /$ Ery B & $\mathrm{NiO} /$ EryB/sol & CV 1 & CV 50 & $\mathrm{Ox}$ & Red \\
\hline $\mathrm{I}^{-}$ & & $48.40 / 1.58$ & $48.29 / 1.66$ & $48.42 / 1.59$ & $48.40 / 1.20$ & \\
\hline $\mathrm{I}_{3}{ }^{-}$terminal & & $49.10 / 1.43$ & $49.11 / 1.19$ & $49.12 / 1.49$ & $49.10 / 1.27$ & \\
\hline $\mathrm{I}_{3}{ }^{-}$central & & $49.90 / 1.43$ & $49.91 / 1.19$ & $49.92 / 1.49$ & $49.90 / 1.18$ & \\
\hline EryB & $50.19 / 1.44$ & $50.44 / 1.26$ & $50.24 / 1.39$ & $50.37 / 1.27$ & $50.30 / 1.10$ & $50.28 / 1.29$ \\
\hline
\end{tabular}

Table 2. Relative Molar ${ }^{a}$ Percentage (\%) of the Different Iodinated Species ${ }^{b}$ onto $\mathrm{NiO}$, As Obtained by the Area of the Components Used To Deconvolute the I 4d XP Spectra ${ }^{c}$

\begin{tabular}{|ccccc}
\multicolumn{5}{c}{ samples } \\
& $\mathrm{NiO} /$ EryB/sol & CV 1 & CV 50 & Ox \\
\hline $\mathrm{I}^{-}$ & 87.6 & 79.0 & 82.6 & 65.5 \\
$\mathrm{I}_{3}{ }^{-}$ & 5.0 & 11.0 & 10.3 & 31.1 \\
EryB & 7.4 & 11.0 & 7.1 & 3.4
\end{tabular}

${ }^{a}$ In order to obtain the molar ratio, the peak related to the central I in $\mathrm{I}_{3}{ }^{-}$species was selected, whereas the area of the peak related to EryB was divided by $4 .{ }^{b}$ The $\mathrm{NiO} / \mathrm{EryB}$ and Red samples were found to contain only the EryB species. ${ }^{c}$ The calculation of the area of XPS signals was performed on the $\mathrm{I}^{4} \mathrm{~d}_{5 / 2}$ spin-orbit components.

found in minor relative concentration (see Table 2), and its molar amount relative to $\mathrm{NiO}$ on passing from the $\mathrm{NiO} / \mathrm{EryB}$ to the $\mathrm{NiO} / \mathrm{EryB} /$ sol sample decreases too (see Figure $7 \mathrm{a}$ and Table 3). This decrease after dipping in the electrolyte solution is likely attributable to a partial attenuation of the photoelectron coming from the adsorbed dye exerted by a fraction of the overlying redox couple species. This eventually hampers a direct quantitative comparison between the reference $\mathrm{NiO}$ /

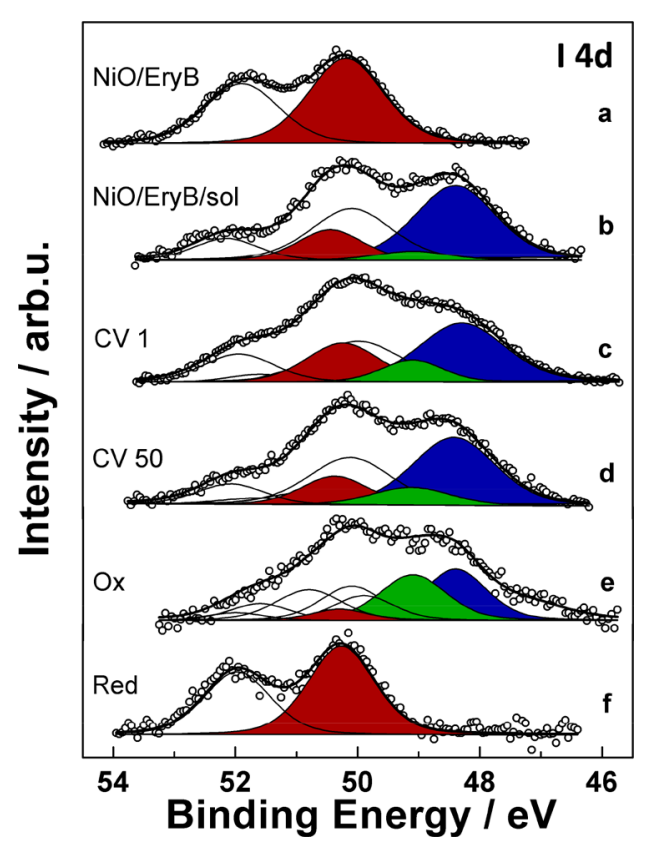

Figure 7. I 4d XP regions for all the samples described. Samples from top to bottom: NiO/EryB (a), NiO/EryB/sol (b), CV 1 (c), CV 50 (d), Ox (e), and Red (f). The experimental data (dots) have been theoretically reconstructed via a peak-fitting procedure (continuous lines). The $j=5 / 2$ components are colored according to the different iodine compounds. Blue: $\mathrm{I}^{-}$; green: central $\mathrm{I}$ atom in $\mathrm{I}_{3}^{-}$; red: $\mathrm{I}$ atoms in EryB.
EryB sample and the unreacted $\mathrm{NiO} /$ EryB/sol system (Figure $7 \mathrm{a}, \mathrm{b})$.

Bearing in mind the general distribution of the various chemical components within the I $4 \mathrm{~d}$ envelope, we pass now to examine the effects induced by the electrochemical treatments. Sample CV 1 underwent one potential cycling via CV, and its I $4 \mathrm{~d}$ spectrum is reported in Figure $7 \mathrm{c}$. In this case, the relative molar amounts (Table 2) of both $\mathrm{I}_{3}{ }^{-}$and EryB moderately increase, the former probably due to oxidation of $\mathrm{I}^{-}$ions, followed by inefficient release of the freshly formed $\mathrm{I}_{3}{ }^{-}$ions from the $\mathrm{NiO}$ pores to the solution, as already previously observed in the absence of the dye. ${ }^{33}$ As to the relative increase in the EryB signal, this might be associated to a more homogeneous dispersion of the redox couple anions within the pores of the electrode and in proximity of the freshly generated $\mathrm{Ni}$ (III) centers driven by the positive polarization during the anodic scan, which would lessen the attenuation effect compared to the probably layered structure derived by the simple dipping ( $\mathrm{NiO} / \mathrm{EryB} / \mathrm{sol})$. Furthermore, it is to be noted that the overall amount of redox couple anions increases after 1 CV cycle (Table 3) because of physical entrapment within the pores and irreversible electrostatic compensation of generated $\mathrm{Ni}$ (III) centers. Upon repeated cycling (CV 50 sample, Figure $7 \mathrm{~d}$ ), the total amount of iodinated species slightly decreases (Table 3), apparently due to a more efficient depletion of the pores from the adsorbed species coupled to a probable partial detachment of the dye molecules. ${ }^{31}$ As reported in Figure 1 and in the electrochemical characterization section, although a small drop is detected in the overall amount of iodinated species after 50 potential cycles, a decrease in the concentration of the electroactive species is experienced in parallel. According to this, a change in the quality of the interaction between the substrate and electrolyte anions may occur along with repeated potential cycling, which causes an irreversible stabilization of an increasing portion of $\mathrm{Ni}$ (III) charged centers.

The oxidation procedure, which implies holding the potential at $0.9 \mathrm{~V}$ for $8000 \mathrm{~s}$ (Ox sample, Figure 7e), produces an increase in the total amount of redox couple anions while holding constant the amount of the EryB dye. Furthermore, the increase is apparently more pronounced for the $\mathrm{I}_{3}{ }^{-}$anion, consistently with its expected electrochemical generation from the oxidation of $\mathrm{I}^{-}$ions at the potential applied and can be attributed to an accumulation of the hindered triiodide anions within the $\mathrm{NiO}$ pores and their hampered diffusion back to the solution bulk. This enrichment of the surface with redox couple anions is fully consistent with what was found in the case of bare $\mathrm{NiO}$ in the same solution. ${ }^{33}$

As a conclusive spectrum, in Figure $7 \mathrm{f}$ the one relative to the sample reduced by holding the potential at $-0.27 \mathrm{~V}$ for $8000 \mathrm{~s}$ (Red sample) is reported. This spectrum presents only the I component from the EryB dye, suggesting that upon negative polarization the electrode surface is depleted from all the 
Table 3. Quantification of Iodinated Species onto NiO Obtained from XPS I/Ni Atomic Ratios

\begin{tabular}{|c|c|c|c|c|c|c|}
\hline \multicolumn{7}{|c|}{ samples } \\
\hline & $\mathrm{NiO} /$ Ery B & $\mathrm{NiO} /$ EryB/sol & CV 1 & CV 50 & $\mathrm{Ox}$ & Red \\
\hline $\mathrm{I}_{\text {tot }} / \mathrm{NiO}$ & 0.032 & 0.022 & 0.050 & 0.045 & 0.095 & 0.007 \\
\hline $\mathrm{I}^{-} / \mathrm{NiO}$ & & 0.019 & 0.039 & 0.037 & 0.062 & \\
\hline $\mathrm{I}_{3}^{-} / \mathrm{NiO}$ & & 0.001 & 0.005 & 0.004 & 0.029 & \\
\hline EryB/NiO & 0.008 & 0.002 & 0.005 & 0.003 & 0.003 & 0.002 \\
\hline
\end{tabular}

strongly and weakly adsorbed negative ions. On the other hand, the EryB molecule experiences partial detachment upon prolonged negative polarization. This behavior is in general agreement with what we recently reported for the same $\mathrm{NiO} /$ EryB system in contact with a $\mathrm{LiClO}_{4} / \mathrm{ACN}$ solution undergoing the same kind of electrochemical treatments. ${ }^{31}$ However, in that case, a more dramatic impact of electrochemical stress on surface-immobilized EryB was evidenced. In particular, when potential cycles were continuously applied, a strong interaction between charge compensating $\mathrm{ClO}_{4}^{-}$anions and the defective/oxidized sites of the $\mathrm{NiO}$ surface was established, with the more facile detachment of the dye as a possible consequence.

Overall, as evidenced by the I $4 \mathrm{~d}$ spectra reported in Figure 7 and from the comparison with previously reported results, the presence of the chemisorbed dye exerts a moderate passivation of those defective sites in $\mathrm{NiO}$ which may act as ion-trapping centers. In fact, the adsorption of redox couple anions induced by different electrochemical treatments applied to simulate the possible conditions the cathode may encounter upon operation in a real DSC is in the present case easily canceled out by a potentiostatic reductive polarization (see the Red sample), which calls for a less intimate interaction between the substrate and the electrolyte anions. Instead, in the absence of the dye, ${ }^{33}$ an irreversible stabilization of native and/or electrochemically generated $\mathrm{Ni}$ (III) sites is carried out by the iodide and triiodide anions and is hard to recover even with prolonged reductive polarization. ${ }^{33}$

As to the behavior of the immobilized EryB dye, it turns out that the presence of the $\mathrm{I}_{3}^{-} / \mathrm{I}^{-}$couple in the electrolyte constitutes an advantageous condition in terms of stability of the dye molecule, with respect to the situation in which the electrolyte in contact with EryB-sensitized $\mathrm{NiO}$ contains only the supporting electrolyte $\mathrm{LiClO}_{4} \cdot{ }^{31}$

Likely, the decrease of I signal after the electrochemical treatment is associated with the detachment of the EryB dye from the $\mathrm{NiO}$ electrode. This is coherent with the observations of the electrochemical tests: as evidenced in Figure 1, upon repeated potential cycling, a decrease of faradic current was recorded and the voltammogram of cycled $\mathrm{NiO} /$ EryB becomes progressively similar to the one of bare $\mathrm{NiO}$ with the observation of a quasi-complete overlap after 50 cycles of potential scan (Figure 1).

I $3 d$. Figure 8 reports the I $3 d$ photoionization region for all the samples investigated. The I $3 \mathrm{~d}$ spectra appear as a mixture of well-resolved spin-orbit split doublets $\left(\Delta \mathrm{E}_{\mathrm{so}}=11.4 \mathrm{eV}\right)$ with a symmetrical shape (except for $\mathrm{Mg} \mathrm{K} \alpha$ ghost lines). ${ }^{59}$ The $3 d_{5 / 2}$ component of EryB is located at $620.50 \mathrm{eV}$ (red filled curves in Figure 8) compatibly with other alkyl- and aryliodide systems, ${ }^{6-63}$ significantly higher than the mixed contribution of $\mathrm{I}^{-}$and $\mathrm{I}_{3}^{-}$species (cyan filled curves in Figure 8 ), which are enclosed in a single component, because of the irrelevant chemical shift effect between them, as reported in our previous work. ${ }^{33}$ The relative intensities of the dye and

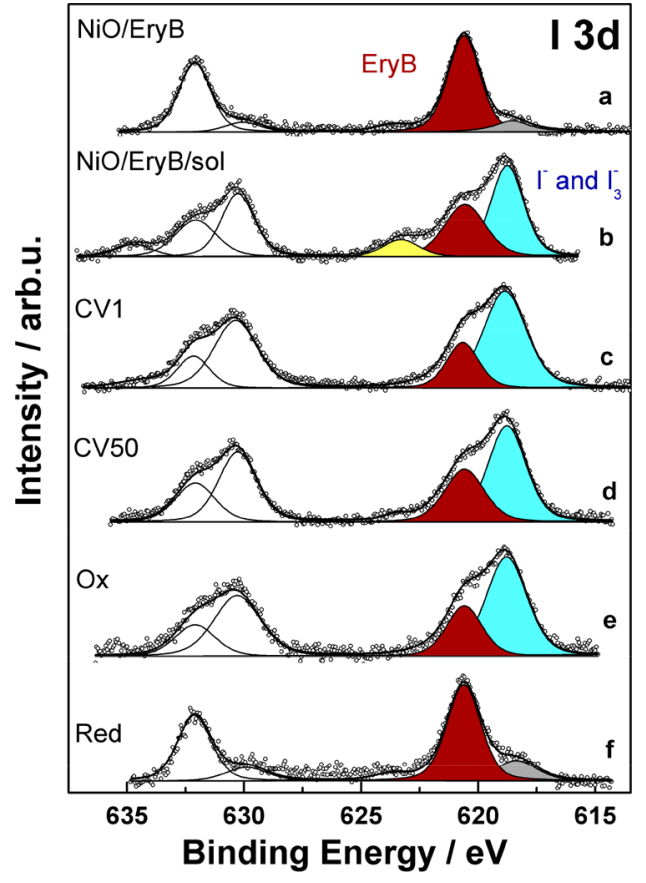

Figure 8. I 3d XP regions for all the samples described. Samples from top to bottom: $\mathrm{NiO} / \mathrm{EryB}(\mathrm{a}), \mathrm{NiO} / \mathrm{EryB} /$ sol (b), CV 1 (c), CV 50 (d), Ox (e), and Red (f). The experimental data (dots) have been theoretically reconstructed via a peak-fitting procedure, whose results are presented with continuous lines. See text for assignments.

electrolyte ion contributions qualitatively follow the trend observed in the I $4 \mathrm{~d}$ region, confirming, for example, the absence of a contribution related to the redox couple anions in the Red sample. On the other hand, a general caution must be taken in comparing I $4 \mathrm{~d}$ and I $3 \mathrm{~d}$ spectra because the chemical information provided by the latter is related to a more superficial portion of the $\mathrm{NiO} /$ dye/electrolyte system because of the lower kinetic energy of outgoing I $3 \mathrm{~d}$ photoelectrons. Furthermore, an additional component was variably detected in the I $3 \mathrm{~d}$ spectra of these samples, here evidenced with gray color in Figure 8a,f. This minor doublet is located $\sim 2 \mathrm{eV}$ lower than the main one and is probably due to the degradation of the EryB dye upon prolonged X-ray exposure. Its occurrence is limited to I $3 \mathrm{~d}$ signals because these were always acquired after the I $4 \mathrm{~d}$ region, thus after longer $\mathrm{X}$-ray exposures. An additional positively shifted component $(+5.2 \mathrm{eV}$ vs anion peak, yellow curve in Figure $8 \mathrm{~b}$ ) was necessary to reconstruct the $\mathrm{NiO} /$ EryB/sol sample spectrum, which is difficult to account for unless the possibility of differential electrostatic charging is considered, probably arising from portions of the porous film where the electrolyte anions are inefficiently contacted with the substrate. As commented above, the application of potential cycling (CV 1 sample) would induce a more homogeneous dispersion of anions on the surface, thus eliminating this issue. 
Ni $2 p$. In Figure 9, the Ni $2 \mathrm{p}_{3 / 2}$ regions are reported for all the sample studied in this work. The line shape of all the

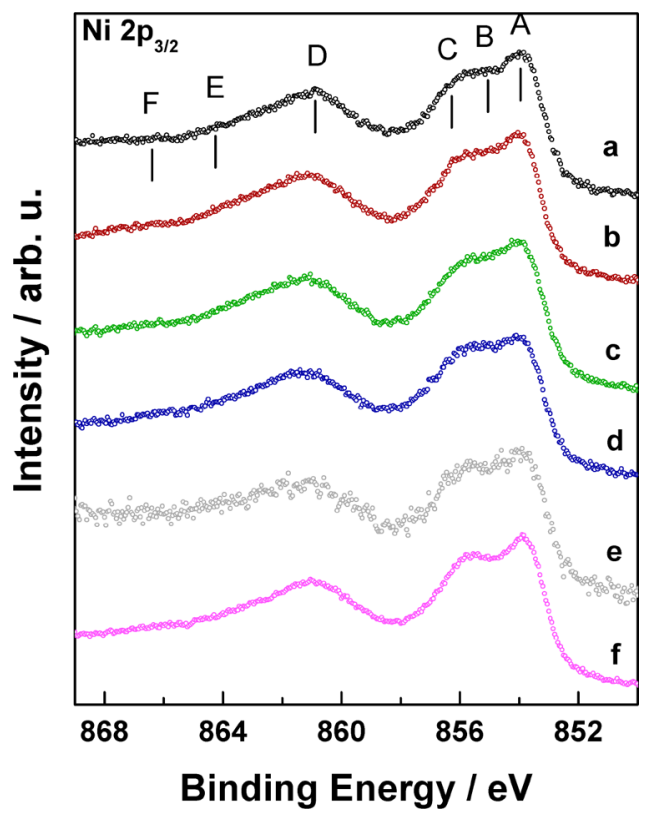

Figure 9. Ni $2 \mathrm{p}_{3 / 2}$ XPS region. Samples from top to bottom: $\mathrm{NiO} /$ EryB (a), NiO/EryB/sol (b), CV 1 (c), CV 50 (d), Ox (e), and Red (f). Main components contributing to the $\mathrm{Ni} 2 \mathrm{p}_{3 / 2}$ envelope are indicated with lines and capital letters from A to F (see the text for details).

spectra reveals the typical envelope of $\mathrm{NiO},{ }^{64-67}$ whose detailed description can be found elsewhere. ${ }^{30,64,66,67}$ As a good compromise between conciseness and completeness, in this work, the different contributions to the overall spectrum are simply indicated by lines with capital letters from $\mathrm{A}$ to $\mathrm{F}$. The first (A) more intense peak is attributed to the $\mathrm{cd}^{9} \underline{\mathrm{L}}$ state ( $\underline{c}$ and $\underline{L}$, respectively, represent holes in the $2 p$ level and in a ligand orbital), ${ }^{66-68}$ whereas $\mathrm{B}$ and $\mathrm{C}$ contributions are associated with core-hole screening processes occurring at the surface, where the bulk symmetry is reduced and the coordination geometry around $\mathrm{Ni}$ is lowered from the octahedral $\mathrm{NiO}_{6}$ to the square-pyramidal $\mathrm{NiO}_{5} \cdot{ }^{65,67,69}$ Components from $\mathrm{D}$ to $\mathrm{F}$ are also typical of $\mathrm{NiO}$ and respectively associated with $\underline{\mathrm{c}} \mathrm{d}^{10} \underline{\mathrm{L}}^{2}$ and $\underline{\mathrm{cd}} \mathrm{d}^{8}$ final states and a shake-up transition. ${ }^{64,70-72}$ Although $\mathrm{NiO}$ is undoubtedly an off-stoichiometric compound with $\mathrm{Ni}^{3+}$ defects, during the years it has been widely accepted ${ }^{70,73}$ that recognition of $\mathrm{a} \mathrm{Ni}^{3+}$ feature within the $\mathrm{Ni} 2 \mathrm{p}$ photoionization envelope cannot be operated unless a genuine $\mathrm{Ni}$ (III) compound is actually under consideration, such as in $\mathrm{NiOOH}$ polymorphs. ${ }^{30,72}$ The close similarity among the $\mathrm{Ni} 2 \mathrm{p}$ spectra in Figure 9 suggests that in this $\mathrm{NiO} /$ dye/(nonaqueous) electrolyte complex interface, the possible electrochemically induced generation of $\mathrm{Ni}$ (III) and $\mathrm{Ni}(\mathrm{IV})$ centers leaves no detectable trace in the Ni $2 \mathrm{p} \mathrm{XP}$ spectrum. $^{32}$

\section{CONCLUSIONS}

Photocathodes for p-DSCs were obtained by the sensitization of nanostructured $\mathrm{NiO}$ films. The mesoporous films of $\mathrm{NiO}$ were deposited by means of a screen-printing technique onto FTO transparent electrodes and were successively dipped in an EryB dye solution. The obtained material was contacted to the nonaqueous electrolyte $(\mathrm{ACN})$ containing the $\mathrm{I}_{3}{ }^{-} / \mathrm{I}^{-}$redox couple, with the aim of studying the dynamics of adsorption at the triple semiconductor/dye/electrolyte interface following electrochemical treatments in dark conditions. Such treatments involved both voltammetric and chronoamperometric polarization programs and were devised in order to simulate the electrical environment the $\mathrm{NiO} /$ dye system experiences in illuminated DSCs.

The current originated by the oxidation of iodide at the EryB/NiO electrode surpasses considerably the current originated by the same redox event at a bare $\mathrm{NiO}$ electrode. The effects induced by the sensitization of $\mathrm{NiO}$ with EryB consisted in the promotion of the adsorptive properties of the starting species $\mathrm{I}^{-}$and in the improvement of the capability of the electrode to desorb the triiodide anions, which are formed upon reversal of the potential scan. Moreover, from the analysis of electrochemical and XPS data, we could not exclude the existence of a catalytic effect exerted by the immobilized molecules of EryB. This effect would consist in the involvement of the I atoms of EryB as initiators/mediators of iodide oxidation. The latter mechanistic hypothesis is supported by the verification of a progressive detachment of the anchored dye upon prolongation of electrochemical cycling.

The analysis of I $4 \mathrm{~d}$ and I $3 \mathrm{~d}$ XP spectra evidenced that the presence of the chemisorbed dye both exerts a moderate passivating action of those defective sites in $\mathrm{NiO}$ which may act as ion-trapping centers and ensures an enrichment of the redox couple species at the surface of the electrode. Such findings are fully coherent with the current enhancement of sensitized versus unsensitized $\mathrm{NiO}$ electrode recorded in the first voltammetric cycle. Oxidative potentiostatic polarization led to an enrichment of the $\mathrm{NiO} /$ EryB system with triiodide, as expected. Instead, the adsorption of both redox couple anions was in the present case easily canceled out by a potentiostatic reductive polarization. As to the behavior of the immobilized EryB dye, the XP spectra revealed that the presence of the $\mathrm{I}_{3}{ }^{-} /$ $\mathrm{I}^{-}$couple in the electrolyte constitutes an advantageous condition in terms of stability of the dye molecular (mono)layer.

The results obtained constitute a significant step forward in the understanding of the basic mechanisms of adsorption governing the electrochemical reactions at the semiconductor/ dye/electrolyte interfaces typical of DSC devices. Such understanding represents a considerable progress in the further definition of viable routes for the inhibition of deleterious recombination phenomena in DSCs.

\section{ASSOCIATED CONTENT}

\section{S Supporting Information}

The Supporting Information is available free of charge on the ACS Publications website at DOI: 10.1021/acsomega.8b02543.

Field emission scanning electron microscopy images of a nanostructured screen-printed bare $\mathrm{NiO}$ sample (PDF)

\section{AUTHOR INFORMATION}

\section{Corresponding Authors}

*E-mail: andrea.marrani@uniroma1.it. Phone: +39 0649913344. Fax: +39 06490324 (A.G.M.).

*E-mail: danilo.dini@uniroma1.it. Phone: +390649913986. Fax: +39 06490631 (D.D.). 


\section{ORCID}

Andrea G. Marrani: 0000-0002-3203-9642

Matteo Bonomo: 0000-0002-1944-2664

Danilo Dini: 0000-0001-5005-4187

\section{Notes}

The authors declare no competing financial interest.

\section{ACKNOWLEDGMENTS}

D.D. acknowledges the financial support from the University of Rome "LA SAPIENZA" through the programs Ateneo 2012 (protocol no. C26A124AXX) and Ateneo 2016.

\section{REFERENCES}

(1) Sk, M. M.; Yue, C. Y.; Ghosh, K.; Jena, R. K. Review on advances in porous nanostructured nickel oxides and their composite electrodes for high-performance supercapacitors. J. Power Sources 2016, 308, 121-140.

(2) Wen, R.-T.; Granquist, C. G.; Niklasson, G. A. Anodic Electrochromism for Energy-Efficient Windows: Cation/AnionBased Surface Processes and Effects of Crystal Facets in Nickel Oxide Thin Films. Adv. Funct. Mater. 2015, 25, 3359-3370.

(3) Gibson, E. A.; Smeigh, A. L.; Le Pleux, L.; Fortage, J.; Boschloo, G.; Blart, E.; Pellegrin, Y.; Odobel, F.; Hagfeldt, A.; Hammarström, L. A p-Type NiO-Based Dye-Sensitized Solar Cell with an Open-Circuit Voltage of 0.35 V. Angew. Chem., Int. Ed. 2009, 48, 4402-4405.

(4) Li, L.; Gibson, E. A.; Qin, P.; Boschloo, G.; Gorlov, M.; Hagfeldt, A.; Sun, L. Double-Layered NiO Photocathodes for p-Type DSSCs with Record IPCE. Adv. Mater. 2010, 22, 1759-1762.

(5) Li, L.; Duan, L.; Wen, F.; Li, C.; Wang, M.; Hagfeldt, A.; Sun, L. Visible light driven hydrogen production from a photo-active cathode based on a molecular catalyst and organic dye-sensitized p-type nanostructured NiO. Chem. Commun. 2012, 48, 988-990.

(6) Meng, P.; Wang, M.; Yang, Y.; Zhang, S.; Sun, L. CdSe quantum dots/molecular cobalt catalyst co-grafted open porous $\mathrm{NiO}$ film as a photocathode for visible light driven $\mathrm{H}_{2}$ evolution from neutral water. J. Mater. Chem. A 2015, 3, 18852-18859.

(7) Irwin, M. D.; Buchholz, D. B.; Hains, A. W.; Chang, R. P. H.; Marks, T. J. p-Type semiconducting nickel oxide as an efficiencyenhancing anode interfacial layer in polymer bulk-heterojunction solar cells. Proc. Natl. Acad. Sci. U.S.A. 2008, 105, 2783-2787.

(8) Bonomo, M. Synthesis and characterization of $\mathrm{NiO}$ nanostructures: a review. J. Nanopart. Res. 2018, 20, 222.

(9) Powar, S.; Wu, Q.; Weidelener, M.; Nattestad, A.; Hu, Z.; Mishra, A.; Bäuerle, P.; Spiccia, L.; Cheng, Y.-B.; Bach, U. Improved photocurrents for p-type dye-sensitized solar cells using nanostructured nickel(ii) oxide microballs. Energy Environ. Sci. 2012, 5, $8896-8900$.

(10) Nattestad, A.; Mozer, A. J.; Fischer, M. K. R.; Cheng, Y.-B.; Mishra, A.; Bäuerle, P.; Bach, U. Highly efficient photocathodes for dye-sensitized tandem solar cells. Nat. Mater. 2009, 9, 31-35.

(11) Awais, M.; Dowling, D. D.; Rahman, M.; Vos, J. G.; Decker, F.; Dini, D. Spray-deposited $\mathrm{NiO}_{x}$ films on ITO substrates as photoactive electrodes for p-type dye-sensitized solar cells. J. Appl. Electrochem. 2012, 43, 191-197.

(12) Bonomo, M.; Dini, D. Nanostructured p-type semiconductor electrodes and photoelectrochemistry of their reduction processes. Energies 2016, 9, 373.

(13) Nakasa, A.; Usami, H.; Sumikura, S.; Hasegawa, S.; Koyama, T.; Suzuki, E. A High Voltage Dye-sensitized Solar Cell using a Nanoporous NiO Photocathode. Chem. Lett. 2005, 34, 500-501.

(14) Hagfeldt, A.; Boschloo, G.; Sun, L.; Kloo, L.; Pettersson, H. Dye-Sensitized Solar Cells. Chem. Rev. 2010, 110, 6595-6663.

(15) Cavallo, C.; Di Pascasio, F.; Latini, A.; Bonomo, M.; Dini, D. Nanostructured Semiconductor Materials for Dye-Sensitized Solar Cells. J. Nanomater. 2017, 2017, 5323164.

(16) Naponiello, G.; Venditti, I.; Zardetto, V.; Saccone, D.; Di Carlo, A.; Fratoddi, I.; Barolo, C.; Dini, D. Photoelectrochemical character- ization of squaraine-sensitized nickel oxide cathodes deposited via screen-printing for p-type dye-sensitized solar cells. Appl. Surf. Sci. 2015, 356, 911-920.

(17) Gerischer, H.; Michel-Beyerle, M. E.; Rebentrost, F.; Tributsch, $\mathrm{H}$. Sensitization of charge injection into semiconductors with large band gap. Electrochim. Acta 1968, 13, 1509-1515.

(18) Weidelener, M.; Mishra, A.; Nattestad, A.; Powar, S.; Mozer, A. J.; Mena-Osteritz, E.; Cheng, Y.-B.; Bach, U.; Bäuerle, P. Synthesis and characterization of perylene-bithiophene-triphenylamine triads: studies on the effect of alkyl-substitution in p-type $\mathrm{NiO}$ based photocathodes. J. Mater. Chem. 2012, 22, 7366-7379.

(19) Qin, P.; Zhu, H.; Edvinsson, T.; Boschloo, G.; Hagfeldt, A.; Sun, L. Design of an Organic Chromophore for P-Type DyeSensitized Solar Cells. J. Am. Chem. Soc. 2008, 130, 8570-8571.

(20) Ameline, D.; Diring, S.; Farre, Y.; Pellegrin, Y.; Naponiello, G.; Blart, E.; Charrier, B.; Dini, D.; Jacquemin, D.; Odobel, F. Isoindigo derivatives for application in p-type dye sensitized solar cells. RSC Adv. 2015, 5, 85530-85539.

(21) Hagfeldt, A.; Graetzel, M. Light-induced redox reactions in nanocrystalline systems. Chem. Rev. 1995, 95, 49-68.

(22) Polo, A. S.; Itokazu, M. K.; Murakami Iha, N. Y. Metal complex sensitizers in dye-sensitized solar cells. Coord. Chem. Rev. 2004, 248, $1343-1361$.

(23) Ooyama, Y.; Harima, Y. Photophysical and Electrochemical Properties, and Molecular Structures of Organic Dyes for DyeSensitized Solar Cells. ChemPhysChem 2012, 13, 4032-4080.

(24) Nellist, M. R.; Laskowski, F. A. L.; Lin, F.; Mills, T. J.; Boettcher, S. W. Semiconductor-Electrocatalyst Interfaces: Theory, Experiment, and Applications in Photoelectrochemical Water Splitting. Acc. Chem. Res. 2016, 49, 733-740.

(25) Boschloo, G.; Hagfeldt, A. Characteristics of the iodide/ triiodide redox mediator in dye-sensitized solar cells. Acc. Chem. Res. 2009, 42, 1819-1826.

(26) Bonomo, M.; Sheehan, S.; Dowling, D. P.; Gontrani, L.; Dini, D. First Evidence of Electrode Reconstruction in Mesoporous $\mathrm{NiO}$ After Operation as Photocathode of Dye-Sensitized Solar Cells. ChemistrySelect 2018, 3, 6729-6736.

(27) Peck, M. A.; Langell, M. A. Comparison of nanoscaled and bulk $\mathrm{NiO}$ structural and environmental characteristics by XRD, XAFS, and XPS. Chem. Mater. 2012, 24, 4483-4490.

(28) Giustini, M.; Angelone, D.; Parente, M.; Dini, D.; Decker, F.; Lanuti, A.; Reale, A.; Brown, T.; di Carlo, A. Emission spectra and transient photovoltage in dye-sensitized solar cells under stress tests. J. Appl. Electrochem. 2012, 43, 209-215.

(29) Venditti, I.; Barbero, N.; Russo, M. V.; Di Carlo, A.; Decker, F.; Fratoddi, I.; Barolo, C.; Dini, D. Electrodeposited ZnO with squaraine sentisizers as photoactive anode of DSCs. Mater. Res. Express 2014, 1, 015040.

(30) Marrani, A. G.; Novelli, V.; Sheehan, S.; Dowling, D. P.; Dini, D. Probing the Redox States at the Surface of Electroactive Nanoporous NiO Thin Films. ACS Appl. Mater. Interfaces 2013, 6, 143-152.

(31) Bonomo, M.; Dini, D.; Marrani, A. G.; Zanoni, R. X-ray photoelectron spectroscopy investigation of nanoporous $\mathrm{NiO}$ electrodes sensitized with Erythrosine B. Colloids Surf., A 2017, 532, 464471.

(32) Bonomo, M.; Marrani, A. G.; Novelli, V.; Awais, M.; Dowling, D. P.; Vos, J. G.; Dini, D. Surface properties of nanostructured $\mathrm{NiO}$ undergoing electrochemical oxidation in 3-methoxy-propionitrile. Appl. Surf. Sci. 2017, 403, 441-447.

(33) Bonomo, M.; Dini, D.; Marrani, A. G. Adsorption Behavior of $\mathrm{I}_{3}{ }^{-}$and $\mathrm{I}^{-}$Ions at a Nanoporous $\mathrm{NiO} /$ Acetonitrile Interface Studied by X-ray Photoelectron Spectroscopy. Langmuir 2016, 32, 1154011550.

(34) Sheehan, S.; Naponiello, G.; Odobel, F.; Dowling, D. P.; Di Carlo, A.; Dini, D. Comparison of the photoelectrochemical properties of RDS $\mathrm{NiO}$ thin films for p-type DSCs with different organic and organometallic dye-sensitizers and evidence of a direct 
correlation between cell efficiency and charge recombination. J. Solid State Electrochem. 2014, 19, 975-986.

(35) Gregg, B. A. Interfacial processes in the dye-sensitized solar cell. Coord. Chem. Rev. 2004, 248, 1215-1224.

(36) He, J.; Lindström, H.; Hagfeldt, A.; Lindquist, S.-E. Dyesensitized nanostructured p-type nickel oxide film as a photocathode for a solar cell. J. Phys. Chem. B 1999, 103, 8940-8943.

(37) Vera, F.; Schrebler, R.; Muñoz, E.; Suarez, C.; Cury, P.; Gómez, H.; Córdova, R.; Marotti, R. E.; Dalchiele, E. A. Preparation and characterization of Eosin B- and Erythrosin J-sensitized nanostructured $\mathrm{NiO}$ thin film photocathodes. Thin Solid Films 2005, $490,182-188$.

(38) Ito, S.; Chen, P.; Comte, P.; Nazeeruddin, M. K.; Liska, P.; Péchy, P.; Grätzel, M. Fabrication of screen-printing pastes from $\mathrm{TiO} 2$ powders for dye-sensitised solar cells. Prog. Photovoltaics Res. Appl. 2007, 15, 603-612.

(39) Bonomo, M.; Barbero, N.; Matteocci, F.; Di Carlo, A.; Barolo, C.; Dini, D. Beneficial Effect of Electron-Withdrawing Groups on the Sensitizing Action of Squaraines for p-Type Dye-Sensitized Solar Cells. J. Phys. Chem. C 2016, 120, 16340-16353.

(40) Bonomo, M.; Naponiello, G.; Dini, D. Oxidative dissolution of $\mathrm{NiO}$ in aqueous electrolyte: An impedance study. J. Electroanal. Chem. 2018, 816, 205-214.

(41) Boschloo, G.; Hagfeldt, A. Spectroelectrochemistry of Nanostructured NiO. J. Phys. Chem. B 2001, 105, 3039-3044.

(42) Yohe, D.; Riga, A.; Greef, R.; Yeager, E. Electrochemical properties of nickel oxide. Electrochim. Acta 1968, 13, 1351-1358.

(43) Tench, D. M.; Yeager, E. Capacitance Measurements on Lithiated Nickel Oxide Electrodes. J. Electrochem. Soc. 1973, 120, 164-171.

(44) Bode, H.; Dehmelt, K.; Witte, J. Zur kenntnis der nickelhydroxidelektrode I. Über das nickel (II)-hydroxidhydrat. Electrochim. Acta 1966, 11, 1079-IN1.

(45) Wehrens-Dijksma, M.; Notten, P. H. L. Electrochemical Quartz Microbalance characterization of $\mathrm{Ni}(\mathrm{OH})_{2}$-based thin film electrodes. Electrochim. Acta 2006, 51, 3609-3621.

(46) Lyons, M. E. G.; Brandon, M. P. The oxygen evolution reaction on passive oxide covered transition metal electrodes in aqueous alkaline solution. Part 1-Nickel. Int. J. Electrochem. Sci. 2008, 3, 13861424.

(47) Scofield, J. H. Hartree-Slater subshell photoionization crosssections at 1254 and $1487 \mathrm{eV}$. J. Electron Spectrosc. Relat. Phenom. 1976, 8, 129-137.

(48) Matsuda, H.; Aoki, K.; Tokuda, K. Theory of electrode reactions of redox couples confined to electrode surfaces at monolayer levels: Part II. Cyclic voltammetry and ac impedance measurements. J. Electroanal. Chem. Interfacial Electrochem. 1987, 217, 15-32.

(49) Gerischer, H.; Scherson, D. A. On the shape of the cyclic voltammetry peaks of species irreversibly adsorbed on electrode surfaces. J. Electroanal. Chem. Interfacial Electrochem. 1985, 188, 3338.

(50) Bonomo, M.; Gatti, D.; Barolo, C.; Dini, D. Effect of Sensitization on the Electrochemical Properties of Nanostructured NiO. Coatings 2018, 8, 232.

(51) Nahon, L.; Svensson, A.; Morin, P. Experimental study of the $4 \mathrm{~d}$ ionization continuum in atomic iodine by photoelectron and photoion spectroscopy. Phys. Rev. A: At., Mol., Opt. Phys. 1991, 43, 2328-2337.

(52) Arbman, M.; Holmberg, S.; Lundholm, M.; Siegbahn, H.; Gropen, O.; Wahlgren, U. ESCA Measurements and ECP Calculations on the 3d Spectrum of $\mathrm{I}_{3}^{-}$. Chem. Phys. 1983, 81, 113-119.

(53) Sherwood, P. M. A. X-Ray Photoelectron Spectroscopic Studies of Some Iodine Compounds. J. Chem. Soc., Faraday Trans. 2 1976, 72, $1805-1820$.

(54) Eriksson, S. K.; Josefsson, I.; Ottosson, N.; Öhrwall, G.; Björneholm, O.; Siegbahn, H.; Hagfeldt, A.; Odelius, M.; Rensmo, H. Solvent dependence of the electronic structure of $\mathrm{I}^{-}$and $\mathrm{I}_{3}^{-}$. J. Phys. Chem. B 2014, 118, 3164-3174.
(55) Josefsson, I.; Eriksson, S. K.; Ottosson, N.; Öhrwall, G.; Siegbahn, H.; Hagfeldt, A.; Rensmo, H.; Björneholm, O.; Odelius, M. Collective hydrogen-bond dynamics dictates the electronic structure of aqueous $\mathrm{I}_{3}^{-}$. Phys. Chem. Chem. Phys. 2013, 15, 20189-20196.

(56) Weber, R.; Winter, B.; Schmidt, P. M.; Widdra, W.; Hertel, I. V.; Dittmar, M.; Faubel, M. Photoemission from Aqueous AlkaliMetal-Iodide Salt Solutions Using EUV Synchrotron Radiation. J. Phys. Chem. B 2004, 108, 4729-4736.

(57) Partanen, L.; Mikkelä, M.-H.; Huttula, M.; Tchaplyguine, M.; Zhang, C.; Andersson, T.; Björneholm, O. Solvation at nanoscale: Alkali-halides in water clusters. J. Chem. Phys. 2013, 138, 044301.

(58) Ottosson, N.; Heyda, J.; Wernersson, E.; Pokapanich, W.; Svensson, S.; Winter, B.; Öhrwall, G.; Jungwirth, P.; Björneholm, O. The influence of concentration on the molecular surface structure of simple and mixed aqueous electrolytes. Phys. Chem. Chem. Phys. 2010, 12, 10693-10700.

(59) Philippe, B.; Park, B.-W.; Lindblad, R.; Oscarsson, J.; Ahmadi, S.; Johansson, E. M. J.; Rensmo, H. Chemical and electronic structure characterization of lead halide perovskites and stability behavior under different exposures-A photoelectron spectroscopy investigation. Chem. Mater. 2015, 27, 1720-1731.

(60) Chen, J.-J.; Winograd, N. The effects of preadsorbed CO on the chemistry of $\mathrm{CH}_{3}$ and $\mathrm{CH}_{3} \mathrm{I}$ on $\mathrm{Pd}\{111\}$. Surf. Sci. 1994, 314, 188200.

(61) Solymosi, F.; Révész, K. study on the adsorption and dissociation of $\mathrm{CH}_{3} \mathrm{I}$ on $\mathrm{Pd}(100)$ : thermal and photo effects. Surf. Sci. 1993, 280, 38-49.

(62) Zhou, X.-L.; Solymosi, F.; Blass, P. M.; Cannon, K. C.; White, J. $\mathrm{M}$. Interactions of methyl halides ( $\mathrm{Cl}, \mathrm{Br}$ and I) with $\mathrm{Ag}(111)$. Surf. Sci. 1989, 219, 294-316.

(63) Zaera, F.; Hoffmann, H. Detection of Chemisorbed Methyl and Methylene Groups: Surface Chemistry of Methyl Iodide on $\mathrm{Pt}(111)$. J. Phys. Chem. 1991, 95, 6297.

(64) Biesinger, M. C.; Payne, B. P.; Lau, L. W. M.; Gerson, A.; Smart, R. S. C. X-ray photoelectron spectroscopic chemical state Quantification of mixed nickel metal, oxide and hydroxide systems. Surf. Interface Anal. 2009, 41, 324-332.

(65) Soriano, L.; Preda, I.; Gutiérrez, A.; Palacín, S.; Abbate, M.; Vollmer, A. Surface effects in the Ni 2p x-ray photoemission spectra of NiO. Phys. Rev. B: Condens. Matter Mater. Phys. 2007, 75, 233417.

(66) Preda, I.; Mossanek, R. J. O.; Abbate, M.; Alvarez, L.; Méndez, J.; Gutiérrez, A.; Soriano, L. Surface contributions to the XPS spectra of nanostructured $\mathrm{NiO}$ deposited on HOPG. Surf. Sci. 2012, 606, $1426-1430$.

(67) Mossanek, R. J. O.; Preda, I.; Abbate, M.; Rubio-Zuazo, J.; Castro, G. R.; Vollmer, A.; Gutiérrez, A.; Soriano, L. Investigation of surface and non-local screening effects in the $\mathrm{Ni} 2 \mathrm{p}$ core level photoemission spectra of NiO. Chem. Phys. Lett. 2011, 501, 437-441.

(68) van Veenendaal, M. A.; Sawatzky, G. A. Nonlocal screening effects in 2p x-ray photoemission spectroscopy core-level line shapes of transition metal compounds. Phys. Rev. Lett. 1993, 70, 2459-2462.

(69) Biju, V.; Khadar, M. A. Electronic structure of nanostructured nickel oxide using Ni 2p XPS analysis. J. Nanopart. Res. 2002, 4, 247253.

(70) van Elp, J.; Eskes, H.; Kuiper, P.; Sawatzky, G. A. Electronic structure of Li-doped NiO. Phys. Rev. B: Condens. Matter Mater. Phys. 1992, 45, 1612-1622.

(71) Alders, D.; Voogt, F. C.; Hibma, T.; Sawatzky, G. A. Nonlocal screening effects in $2 \mathrm{p}$ x-ray photoemission spectroscopy of $\mathrm{NiO}$ (100). Phys. Rev. B: Condens. Matter Mater. Phys. 1996, 54, 77167719.

(72) Grosvenor, A. P.; Biesinger, M. C.; Smart, R. S. C.; McIntyre, N. S. New interpretations of XPS spectra of nickel metal and oxides. Surf. Sci. 2006, 600, 1771-1779.

(73) Kuiper, P.; Kruizinga, G.; Ghijsen, J.; Sawatzky, G. A.; Verweij, $\mathrm{H}$. Character of Holes in $\mathrm{Li}_{\mathrm{x}} \mathrm{Ni}_{1-\mathrm{x}} \mathrm{O}$ and Their Magnetic Behavior. Phys. Rev. Lett. 1989, 62, 221-224. 